\title{
Evaluation of a
}

\section{workshop for survivors: Picking Up the Pieces}

by Margaret Fitch, Alison McAndrew, Sherri Magee, Fran Turner and Elisabeth Ross

\begin{abstract}
As the cadre of cancer survivors grows, more information about the long-term impact of cancer and its treatment is becoming evident. Ovarian Cancer Canada (OCC) responded to identified needs of women who had been treated for ovarian cancer and developed a workshop program for survivors entitled, Picking Up the Pieces. This article describes the evaluation of the workshop, as it was offered to 170 survivors in eight sessions across Canada. The written surveys and in-depth interviews revealed the participants found the workshop very helpful in validating their experiences in coping as a survivor, connecting them with other survivors and a network of support, and providing practical tools to help them move forward to live the lives they envisioned. Cancer nurses are in ideal positions to encourage women to attend workshops designed for survivors. In addition, this program could serve as a model and be adapted for patients with other types of cancer.
\end{abstract}

\section{About the authors

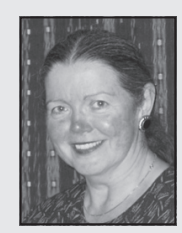 \\ Margaret Fitch, $R N, P h D$, Odette Cancer Centre, 2075 Bayview Ave., Toronto, ON M4N 3M5 \\ Tel: 416-480-5891; Fax: 416-480-7806; \\ Email: marg.fitch@sunnybrook.ca}

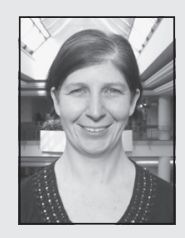

Alison McAndrew, BA, RAP, Odette Cancer Centre, 2075 Bayview Ave., Toronto, ON M4N 3M5. Email: Alison.mcandrew@sunnybrook.ca

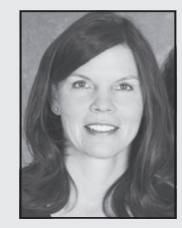

Sherri Magee, PhD, 1660 Angus Dr., Vancouver, BC V6J 4 H3.

Email: sherri@sherrimagee.com
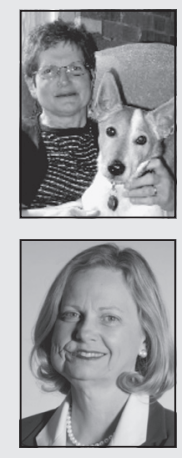

Fran Turner, MS, Ovarian Cancer Canada, 145 Front Street East, Suite 101, Toronto, ON M5A 1 E3. Email: fturner@ovariancanada.org

Elisabeth Ross, MHSc, Ovarian Cancer Canada, 145 Front Street East, Suite 101, Toronto, ON M5A 1E3.

Email: eross@ovariancanada.org

\section{Introduction}

An estimated 2,700 women are diagnosed annually in Canada with ovarian cancer (National Cancer Institute of Canada, 2009). Despite the fact that it is the leading cause of death resulting from gynecologic cancers and many women are still diagnosed with advanced disease (Stage III or IV) (Daly \& Ozols, 2004) when survival is approximately $20 \%$, there are encouraging developments. Increasingly effective and less toxic therapy regimens introduced since the 1970s have steadily increased the survival rates. The number of women living five years following diagnosis of ovarian cancer has increased from 37\% in 1976 to 46\% in 2006 (American Cancer Society [ACS], 2010). Optimal debulking techniques have been cited as one of the significant factors in maximizing the effectiveness of postoperative therapies (Lockwood-Rayermann, 2006).

As the cadre of ovarian cancer survivors grows, evidence is increasing about the challenges these women continue to face. Many have ongoing effects from their surgery and treatment such as infertility, sexuality changes, fatigue, treatment-induced menopause, and cognitive changes (Fitch, Gray, \& Franssen, 2000, 2001; Lockwood-Rayermann, 2006). In some ways, ovarian cancer today could fit into a chronic illness framework. Management of the disease and its symptoms can be an ongoing issue for quite a period of time. The impact is much more than physical. It is emotional, social, psychological and spiritual, as well (Fitch, Porter, \& Page, 2008). Not only must survivors cope with physical late and longterm effects, but they also need to pick up the pieces of their lives and move on.

Survivors of ovarian cancer are challenged to find ways of coping with uncertainty, lack of control, fear of the unknown, the stigma of cancer, and the possibility of recurrence and death (Ferrell et al., 2005; Howell, Fitch, \& Deane, 2003). Changes in family roles, alterations in body function and self-image, changes in comfort and mobility, issues regarding fertility and sexuality, and challenges with cognitive functioning and physical capacity have been described as challenges by survivors. Those who are younger, less educated, un-partnered, and living with more extensive disease experience more challenges (Gil, Gibbons, Jenison, Hopkins, \& van Gruenigen, 2007; Schulman-Green, Ercolano, Dowd, Schwartz, \& McCorkle, 2008).

Ovarian Cancer Canada (OCC) is a national organization whose mission is to overcome ovarian cancer, providing leadership by: 1) supporting women living with the disease and their families, 2) raising awareness in the general public and with health care professionals, and 3) funding research to develop early detection techniques, improved treatment and, ultimately, a cure. Ovarian Cancer Canada learned about many of the issues survivors were experiencing during stakeholder forums and information sessions they held across Canada (Fitch \& Turner, 2004). Women asked for help in coping with the transition from primary treatment of ovarian cancer to living as a survivor, with or without active disease. Ovarian Cancer Canada then sent 18 ovarian cancer survi- 
vors to the International Cancer Rehabilitation Conference in Vancouver (April 2006) where the women attended a Picking Up the Pieces workshop provided by Sherri Magee and Kathy Scalzo. This workshop was designed to introduce the notion of survivorship and some strategies survivors might use to cope with their situation. These survivors who attended the workshop subsequently urged Ovarian Cancer Canada to offer this type of program to other women survivors across Canada. In response to the women's request, Ovarian Cancer Canada developed a new program entitled, Picking Up the Pieces: A Program for Survivors. Working closely with Dr. Sherri Magee, an enlarged workshop format was designed for the new program based on the information and approaches developed by Dr. Magee and her colleague, Kathy Scalzo (Magee \& Scalzo, 2006). Essentially, the new program was expanded to a day in length and allowed a much deeper exploration of survivorship and practical coping strategies. This article will describe the new program for survivors of ovarian cancer and share the evaluation results from its initial implementation across Canada.

\section{Picking up the Pieces program description}

The new program was based on the material outlined in the book entitled, Picking up the pieces: Moving forward after surviving cancer by Magee and Scalzo (2006). The book was written to be a resource for individuals who had undergone cancer treatment, with all of its consequences, and who were facing the challenges of picking up the pieces of their lives, finding a way to put the pieces back together again, and moving on. It combines the voices of many survivors to present a practical guide for recovery and healing after cancer treatment.

The new program was designed as a day-long workshop program for women who had been diagnosed and treated for ovarian

Table 1. Content outline for workshops (six-hour sessions)

Overview of the Four Phases of Recovery

\section{Recovering a Sense of Self-Inquiry \\ Main Questions: \\ What is my new normal? \\ What has changed? \\ What is still the same?}

Puzzle: Finding the four corners-mind, body, spirit, relationships

\section{Recovering a Sense of Control-Discovery \\ Main Questions: \\ What do I need to heal? \\ Am I living the life I want to live?}

Puzzle: Framing in the edges

\section{Recovering a Sense of Meaning-Growth}

Main Question:

What insights have I gained from the experience with cancer?

Puzzle: Working towards the centre

\section{Recovering a Sense of Future-Reflection \\ Main Question: \\ How do I live for today?}

cancer. There were no restrictions regarding time since diagnosis. The program focused on providing practical approaches to recovery after ovarian cancer treatment. The specific objectives were to help women 1) move through the transition from survivor to living well, 2) integrate the pre- and post-cancer self, 3) rebuild confidence in their choices and hope in the future, 4) identify new-found insight and strengths, and 5) ignite or renew their healing spirits. The content and activities were based on four phases of recovery as conceptualized by Magee and Scalzo: inquiry (recovering a sense of self); discovery (recovering a sense of control); growth (recovering a sense of meaning); and reflection (recovering a sense of future) (Magee \& Scalzo, 2006).

The agenda for the workshop included a didactic presentation about the four phases of recovery (including graphic displays in slides), large and small group discussion regarding beliefs about healing and envisioning the way women wanted to live their lives, experiential exercises, and active learning and practice around the foundational skills of the program (see Table 1 for agenda). The foundational skills include the five question check-in and attentive walking (see Table 2).

The program was advertised in each city through Ovarian Cancer Canada publications (e-news and Seeds of Hope) and stakeholder mailings. Participants pre-registered, but were not charged a fee to attend. The workshops were held in local hotel facilities. The new program was run as a six-hour workshop format a total of eight times (Winnipeg, Edmonton, Calgary, Victoria, Halifax, London, Ottawa, and Montreal).

\section{Evaluation data collection and analysis}

The evaluation of the new program was designed to describe the women's perspectives about the workshop and determine how they made use of the information they received and skills they developed. Data were gathered both at the workshop and six months later to determine if the program 1) ran as it was designed to run, and 2) whether it achieved the goals that were set out for it.

Two approaches were used to conduct the evaluation data collection. Firstly, all participants were invited to complete a survey

Table 2. Five Question Check-In and attentive walking

Workshop Encouraged Daily Reflections on 5 Questions*

- What's happening to my body?

- How am I feeling emotionally?

- When I let my thoughts wander, what do I think about?

- Who did I connect with?

- What gave me a sense of peace?

Workshop Encouraged Attentive Walking **

- Set aside 20 minutes to walk alone every day.

- Pay attention to your breath.

- Notice what is happening to your body. What's your stride like? Do you move freely and easily? Where do you feel pain, tightness or discomfort?

- Pay attention to sounds, colours, and smells as you walk.

- Notice the feelings that come up as you give your attention to the world around you.

- Come back to the present moment whenever your mind wanders off.

* See page 67, Picking Up the Pieces (Magee \& Scalzo, 2006)

$* *$ See page 66, Picking Up the Pieces (Magee \& Scalzo, 2006) 
about their perspectives on the workshop at the close of the daylong session. The surveys were gathered by the workshop facilitator and then forwarded to the research coordinator in Toronto. Secondly, participants were invited to participate in a semi-structured telephone interview six months after the workshop. The invitation for the interview was issued at the close of the workshop and participants were contacted specifically about it by the Toronto-based research coordinator six months later. Participants' consent for the interview was obtained at that six-month time point prior to conducting it. The interviews were conducted on the telephone by the research coordinator and audiotaped for notetaking convenience and subsequent analysis.

The evaluation tools were designed for the purposes of this particular work. The post-workshop survey was designed to capture demographic data (i.e., age, time since diagnosis) and perspectives about the actual program delivery. Perspectives were captured by asking the women to rate, on a 4-point Likert scale, various aspects of the workshop (i.e., presentations, handouts, group work, etc.). The survey also included open-ended items asking about participants' suggestions for improvement, plans to use the information and tools from the workshop, and whether they would recommend the program to others.

The six-month interview guide contained questions concerning the women's recollections about the workshop experience, what had been inspiring about the workshop, what had been challenging in attending the workshop, how the workshop learning had been applied, and suggestions for improving any future workshops. The expectation was the interview would take about 20 to 30 minutes, depending on how much detail the women wanted to provide.

The analysis of the post-session survey was descriptive. Frequencies and percentages were calculated for the responses to each of the closed-ended items. The content from the open-ended items was collated and organized on the basis of similarities in perspectives. The interview data were subjected to a simple content analysis. Responses under each question were collated and grouped on the basis of similar perspectives.

\section{Results \\ Sample}

The data for this evaluation were generated at eight workshops across Canada. A total of 103 individuals completed the written survey at the end of the respective sessions out of the 170 individuals who attended the sessions. The average age of the respondents was 54 years (median 55) with a range of 27 to 74. Of the 103 respondents, 14 were individuals with a type of cancer other than ovarian and six were family members and/or caregivers. Those who had undergone treatment were, on average, 23 months since completion of that treatment (range 0 to 300 months).
Survey ratings and commentary about program elements

Table 3 presents a summary of the ratings for each of the key program elements. Ninety-nine per cent of the participants who responded to the survey rated the workshop overall as "good" to "excellent." They reported handouts were helpful and understandable with the exception of some graphical depictions of the survival/recovery process.

Participants actually wrote many comments on the survey in response to the open-ended questions. Overall, participants thought the facilitator delivered information in an informative and encouraging way. Having a way of visualizing and understanding the steps of recovery helped participants realize what they were experiencing was not unusual.

- I appreciated the emphasis on the positive and use of words: compassion, bravery.

- Very informative; [I have] a better insight into recovery and future.

- The facilitator is very comfortable with the material; she understands what survivors want and need.

Many participants wrote about the value of sharing stories with one another. Hearing the stories from other survivors left them feeling hopeful and encouraged. There was a sense of finding common ground and, therefore, not feeling so alone in the experience of being a survivor.

- [I liked best] hearing other people's stories and going through the whole process of survivorship to living well.

- There is hope. I am not alone. I felt support in the group.

- The sense of hope that [the facilitator] left with us; the fact that choice is so important in how we live.

Some participants described specific tangible aspects of the workshop as being most worthwhile-learning the phases of the recovery process, reviewing the book, Picking Up the Pieces: Moving Forward After Surviving Cancer (Magee \& Scalzo, 2006). Others found the most worthwhile aspect of attending the workshop was the support they received from others. Just being with other survivors was experienced as being supportive.

- [I liked] talking with other people in similar situations who have a better understanding of my experience with cancer.

- [I liked] the opportunities for the attendees to share their insights.

In terms of practical tools women thought they could use, participants identified several they had gained at the workshop. These tools were listed as follows:

- Attentive walking

- Five-point check-in

- Ways to name and understand the fear; practical sense of hope (not "Hallmark" platitudes)

- Knowing that the self I am working to heal is worth working on because it will outlive the body.

Table 3. Helpfulness of various program elements $(\mathrm{N}=103)$

\begin{tabular}{|l|c|c|c|c|}
\hline Elements & $\begin{array}{c}\text { Strongly agree/ } \\
\text { agree }\end{array}$ & Neutral & $\begin{array}{c}\text { Strongly disagree/ } \\
\text { disagree }\end{array}$ & Not applicable \\
\hline $\begin{array}{l}\text { Graphs of the recovery process } \\
\text { were useful }\end{array}$ & 26 & 7 & 1 & 65 \\
\hline Handouts were easy to understand & 96 & 4 & 1 & 5 \\
\hline Handouts were useful & 97 & 5 & 1 & - \\
\hline PowerPoint was helpful & 88 & 13 & 2 & - \\
\hline
\end{tabular}


The women participants indicated they planned to share what they had learned with their family members, as well as using the information themselves.

- I think it's going to help me get through my days a little easier.

Without exception, all participants indicated they would recommend the workshop to other survivors. They saw it would help to validate what people are feeling and what would be helpful to learn in order to cope with the aftermath of treatment.

- This gives great tools for working through the stages after treatment and moving from "the void to the new normal."

\section{Follow-up/interviews at six months}

Thirty-seven women at the end of the workshop session said that they could be contacted in six months for an interview. When actual contact was made, 15 agreed to complete the interview. For the most part, the others declined the follow-up interview because they were not feeling well enough or were no longer interested in participating. The interviews lasted approximately 30 minutes each (range 20 to 60 minutes).

Reflecting back on the actual workshop experience, all interviewees recalled it with positive regard. They remembered the session being complementary to their other experiences and that much positive social interaction had occurred. They described feeling inspired by the other participants, as they heard the various stories. In the words of one interviewee, "That we were there at all was inspiring." The women described how the facilitator and the way she interacted had validated their experience as survivors, and this contributed to the feeling of being inspired. This understanding and its validation were seen as an additional benefit to just seeing all the other participants together in various stages of the illness.

Thinking back over the six months since attending the workshop session, the women who were interviewed described how the workshop had motivated them to make plans for the future. It reinforced what they were feeling or experiencing, allowed them to cultivate new friendships, and gave them a few practical tools they could use. Overall, there was a sense of practical learning about exactly what to do rather than just reading or talking about what to do. The practical tools they had used over the six months included the 5-Question Check-in (see Table 2), attentive walking, journaling, music, and specific meditations they had learned about during the workshop.

Most of the 15 women who were interviewed stated they were living the life they wanted to live at the time of the follow-up interview. They described travelling, gardening, spending time with family, exercising, and living more "in the moment." They expressed a sense the workshop had helped them in thinking about, and taking steps toward achieving the goal of living their lives fully.

\section{Suggestions from the women for} improvements in the workshop

Any suggestions the interviewees made about improving the actual workshop reflected what had been written earlier on the surveys at the end of the workshop session. The key ideas about improvements to the workshop included:

- Make more group time and discussion/increase interaction (more action and less listening)

- Realize it can be challenging to relive the experience by talking about it

- Make the workshop longer (two days or two times)

- The day was long

- Offer same workshop for family/caregivers

- Create a workbook to go with the sessions

- Develop an "indoor" meditation session (to use if you cannot go outdoors for a walk).

\section{Discussion and implications}

There is an increasing number of individuals in Canada who are living after their diagnosis and treatment of cancer. Approximately one million survivors exist in Canada (NCIC, 2009). Survivorship is a fast-growing phenomenon and more attention is being focused on the realities of coping during this period (Boyle, 2006; Fitch, Ristovski-Slijepcevic, Scalzo, Bennie, Nicoll, \& Doll, 2009; Lance Armstrong Foundation, 2004). This has led to a growing body of knowledge and understanding about the long-term impact of cancer and its treatment. For many, there is a need to cope with a variety of late and long-term effects of the cancer treatment, yet also find a way to move beyond the acute episode of treatment itself and carry on with one's life. There is a need for transition between the end of primary treatment and picking up the pieces of one's life and moving forward. To date, the cancer system has not paid a great deal of attention to this interval or to the ways in which individuals can be supported to make a successful transition (Institute of Medicine \& National Research Council, 2005) between primary treatment and living after cancer. The program designed and offered by OCC, thus, is innovative and begins to respond to this gap in supportive care.

This program was designed for ovarian cancer survivors and the participants were self-selected. The evaluation was voluntary and repeated efforts to connect with participants for follow-up did not occur. Nonetheless, based on the evaluation results (written survey and interview data), the new program Picking Up the Pieces was offered as planned and was successful in achieving its objectives (i.e., helping women move through the transitions to living well, integrate their new cancer-self and recovery insights, rebuild confidence, and renew their healing spirits). Of note was the degree of personal validation participants reported they had received. The content of the workshop and the exchange with other participants served to normalize the feelings and concerns women had been experiencing. In particular, the conceptualizations about transition, recovery as a process, and taking back control of one's life were seen as empowering for the participants. Additionally, they now had language to describe what was happening to them. The specific skills they learned (i.e., tools to manage the fears; exercises to explore living the life they want to live; tools to move into their future; self-assessment profiles to explore the physical, spiritual, and social challenges they face) contributed to the sense of doing something active in order to move on after the trauma of the diagnosis and treatment. Clearly, this program spoke to coping with psychosocial quality of life issues and spoke to many of the benefits seen with in-person patient support group activity (Gray, Sinding, \& Fitch, 2001). As a model, it may have considerable applicability for other cancer disease sites or patient populations.

This program was designed and offered by a community volunteer-based agency in partnership with professionals. It was fully supported by the agency and was held in a hotel facility. This could be an approach for future consideration. However, given the relatively new attention to survivorship within the cancer care continuum, as a concept and as an area requiring programmatic approaches, there are questions to be explored: Who ought to take a role and the responsibility for survivorship programs? Where are individuals likely to access programs - at a cancer centre or in the community? How do cancer programs and community-based agencies partner to best advantage around the issues of survivorship? Who ought to be offering what types of programs or content? When should programs that are aimed at survivorship be offered during the cancer experience? These are topics to be debated and clarified.

The number of publications concerning survivorship has escalated over the past several years (Morgan, 2009). However, considerable controversy remains around how approaches to 
survivorship programs and service delivery ought to occur. Much of the focus for service delivery has been on using survivorship care plans as a tool to help patients move toward survivorship. A recent environmental scan concerning the survivorship care plans revealed the following insight: Cancer programs tend to approach survivorship care plans in terms of providing summaries of treatment received, potential side effects to watch for, and instructions for follow-up tests (i.e., mammography, CA-125, etc.), while community-based agencies focus on survivorship as learning about coping, practical assistance, stress management, and healthy lifestyles (http://www.partnershipagainstcancer.ca/sites/default/files/ journey/Survivorship_Svetlana_Ristovski-Slijepcevic.pdf). Surely, future efforts ought to consider finding ways to integrate these aspects of survivorship care and have cancer programs and community-based agencies work in partnership.

\section{References}

American Cancer Society (2010). Cancer facts and figures 2006. Retrieved from http://www.cancer.org/acs/groups/content/ @nho/documents/document/acspc-024113.pdf

Boyle, D.A. (2006). Survivorship. Canadian Journal of Oncology Nursing, 10(3), 407-416.

Daly, M.B., \& Ozols, R.R. (2004). Symptoms of ovarian cancer-Where to set the bar? Journal of the American Medical Association, 291(22), 2755-2756.

Ferrell, B., Cullinane, C.A., Ervine, K., Melancon, C., Uman, G.C., \& Jarez, G. (2005). Perspectives on the impact of ovarian cancer: Women's views of quality of life. Oncology Nursing Forum, 32(6), 1143-1143.

Fitch, M.I., Gray, R.E., \& Franssen, E. (2000). Perspectives on ovarian cancer: Young women's views. Canadian Oncology Nursing Journal, 10(3), 101-108.

Fitch, M.I., Gray, R.E., \& Franssen, E. (2001). Perspectives on living with ovarian cancer: Older women's views. Oncology Nursing Forum, 28(9), 1433-1442.

Fitch, M., \& Turner, F. (2004, May). Canadian stakeholders' perspectives regarding the priorities for information dissemination on ovarian cancer. $2^{\text {nd }}$ National Conference on Ovarian Cancer, Ottawa, Canada.

Fitch, M.I., Porter, H.B., \& Page, B.D. (2008). Supportive care framework: A foundation for person-centred care. Pembroke, ON: Pappin Communications.

Fitch, M., Ristovski-Slijepcevic, S., Scalzo, K., Bennie, F., Nicoll, I., \& Doll, R. (2009). Cancer survivorship: Creating a national agenda. Canadian Oncology Nursing Journal, 19(2), 55-59.

Gil, K.M., Gibbons, H.E., Jenison, E.I., Hopkins, M.P., \& van Gruenigen, V.E. (2007). Baseline characteristics influencing quality of life in women undergoing gynecologic oncology surgery. Health Quality of Life Outcomes, 5, 25.
The program, Picking Up the Pieces, was offered in a workshop format and allowed a personal (face-to-face) interaction. Given its success, the program could be offered in other locations. Oncology nurses could be engaged in planning and offering such a workshop. At the very least, informing patients about any such workshop being held in the local area should be encouraged as part of regular practice. Additionally, there could be adaptations of the program for a broader range of survivors from all types of cancer. It is also reasonable to explore and test adaptations of this program so it can be offered via teleconference or online modalities. Recent experience with online support groups has been very encouraging and has good potential for survivorship care (Stephen et al., 2009). Finally, this type of workshop could be offered to cancer nurses as a way of learning new techniques they could use in their own practice, in their teaching and coaching of survivors, and in their supporting patients and families throughout the transition.

Gray, R.E., Sinding, C., \& Fitch, M.I. (2001). Cancer self-help groups are here to stay: Issues and challenges for health professionals. Journal of Palliative Care, 17(1), 53-58.

Howell, D., Fitch, M.I., \& Deane, K.A. (2003). Impact of ovarian cancer perceived by women. Cancer Nursing, 26(1), 1-9.

Institute of Medicine and National Research Council (2005). From cancer patient to cancer survivor: Lost in transition. Washington, DC: National Academics Press.

Lance Armstrong Foundation. (2004). A national action plan for cancer survivorship: Advancing public health strategies. Austin, TX: Author.

Lockwood-Rayermann, S. (2006). Survivorship issues in ovarian cancer: A review. Oncology Nursing Forum, 33(3), 553-562.

Magee, S., \& Scalzo, K. (2006). Picking up the pieces: Moving forward after surviving cancer. Vancouver: Raincoast.

Morgan, M.A. (2009). Cancer survivorship: History, quality-oflife issues, and the evolving multidisciplinary approach to implications of cancer survivorship care plans. Oncology Nursing Forum, 36(4), 429-436.

National Cancer Institute of Canada. (2009). Canadian cancer statistics 2009. Toronto, ON: Author.

Schulman-Green, D., Ercolano, E., Dowd, M., Schwartz, P., \& McCorkle, R. (2008). Quality of life among women after surgery for ovarian cancer. Palliative Supportive Care, 6(3), 239-247.

Stephen, J., Speca, M., Turner, J., Carlson, L., Taylor-Brown, J., Flood, K., et al. (2009). Empowerment and support at the click of a mouse: Research and clinical developments in professionally facilitated online support groups. Symposium, Canadian Association of Psychosocial Oncology, Vancouver, BC. 